\title{
Aortic Stenosis. Gender Influence on Left Ventricular Geometry and Function in Patients Under 70 Years of Age
}

\author{
Antonio Sérgio Cordeiro da Rocha, Maria Auxiliadora Vellasco Pereira, Nazareth de Novaes Rocha, \\ Rita de Cássia Villela Soares, Celso Garcia, Rosana Grandelle, Paulo Roberto Dutra da Silva
}

\author{
São Paulo, SP - Brazil
}

Objective - To verify if adaptive left ventricle ( $L V)$ characteristics are also present in individuals under 70 years of age with severe aortic stenosis (AS).

Methods - The study comprised 40 consecutive patients under 70 years of age with AS and no associated coronary artery disease, referred for valve surgery. Out of the 40 patients, 22 were men and 18 women, and the mean age was $49.8 \pm 14.3$ years. Cardiac symptoms, presence of systemic hypertension (SH), functional class according to the New York Heart Association (NYHA), and valve lesion etiology were considered. $L V$ cavity dimensions, ejection fraction (EF), fractional shortening (FS), mass (MS), and relative diastolic thickness (RDT) were examined by Doppler echocardiography.

Results - Fourteen (63.6\%) men and 11 (61.6\%) women were classified as NYHA class III/IV $(p=0.70)$. There was no difference in the frequency of angina, syncope or dyspnea between genders. The incidence of SH was greater in women than in men (10 versus 2, $p=0.0044$ ). Women had a smaller LV end-diastolic diameter index (32.1 $16.5 x$ $\left.36.5 \pm 5.3 \mathrm{~mm} / \mathrm{m}^{2}, p=0.027\right), L V$ end-systolic diameter index $\left(19.9 \pm 5.9 \times 26.5 \pm 6.4 \mathrm{~mm} / \mathrm{m}^{2}, p=0.0022\right)$ and $L V$ mass index (MS) (211.4 $\left.\pm 71.1 \times 270.9 \pm 74.9 \mathrm{~g} / \mathrm{m}^{2}, p=0.017\right)$ when compared with men. EF (66.2 $\pm 13.4 \times 52.0 \pm 14.6 \%$, $p=0.0032), F S(37.6 \pm 10.7 \times 27.9 \pm 9.6 \%, p=0.0046)$ and $R D T(0.58 \pm 0.22 \times 0.44 \pm 0.09, p=0.0095)$ were significantly greater in women than in men.

Conclusion - It is the patient gender rather than age that influences left ventricular adaptive response to AS.

Keywords: aortic stenosis, left ventricular function, ventricular hypertrophy, gender

Rio de Janeiro, RJ - Brazil

Hospital de Cardiologia de Laranjeiras, Ministério da Saúde - Rio de Janeiro Mailing address: Antonio Sérgio Cordeiro da Rocha - Rua Roberto Dias Lopes, 220/201 - 22010-110 - Rio de Janeiro, RJ - Brazil.
Recent studies showed that left ventricular response to chronic pressure overload differs between men and women ${ }^{1-3}$. In elder women with severe aortic stenosis (AS), concentrically hypertrophic ventricle with small volumes and normal or supernormal systolic function were observed $^{2-5}$.

Our objective was to verify if these adaptive LV characteristics are peculiar to elder individuals with AS or peculiar to the disease itself. Therefore, we studied a group of patients under 70 years of age with AS and without associated coronary artery disease (CAD).

\section{Methods}

Between June/89 and July/97, 59 consecutive patients underwent surgical correction for isolated or predominant AS in the Hospital de Cardiologia de Laranjeiras, which belongs to the Health Ministry in Rio de Janeiro. Of those patients, 40 were selected: $22(55 \%)$ men and 18 (45\%) women. Their ages were under 70 years (mean age: $49.8 \pm 14.3$ years), and they did not have associated CAD. All of them were symptomatic, showing clinical, electrocardiographic, and radiographic signals compatible with severe aortic valve stenosis and left ventricular-aortic pressure gradient $>50 \mathrm{mmHg}$. Those patients with clinical, echocardiographic or cineangiocardiographic signals of moderate or severe aortic valve regurgitation, or moderate or severe mitral lesions were excluded from the study.

Clinical findings included: cardiac symptoms, presence of systemic hypertension ( $\mathrm{SH}$ ) and functional class according to the New York Heart Association (NYHA). The etiology of AS was determined based upon echocardiographic, surgical and pathological data. In five cases (three men and two women), the etiology of the lesion could not be determined because of the severe calcification and deformation of the valve structure.

All patients underwent echocardiographic examination with continuous Doppler, with or without color, using Interspect, Esaote SIM 5000, Apogee CX100 or 
Apogee CX200 equipiments. The examinations were performed according to conventional techniques and the echocardiographic measurements complied with the American Society of Echocardiography guidelines ${ }^{6}$. To calculate the LV ejection fraction (EF), the Teichholtz method was used ${ }^{7}$, and to calculate the LV mass, the method modified by Devereux et $\mathrm{al}^{8}$ was used. To assess the degree of left ventricular hypertrophy (LVH), the relative diastolic thickness (RDT) was used, a method proposed by Reichek et $\mathrm{al}^{9}$ and consisting of the division of twice the value of the diastolic thickness of the LV posterior wall (PW) by the LV enddiastolic diameter (DD). Cavitary diameters and LV mass were corrected for body surface. Examinations were performed $39 \pm 28$ days before surgery.

All patients, except five, underwent cardiac catheterization. Examinations were performed according to Sones or Judkins' techniques and served to basically study coronary artery circulation.

Numeric data are expressed by mean and standard deviation. For comparison between continuous variables, the two-tailed nonpaired Student's $t$ test was used, and for comparison between proportions, the chi-square test with Yates' correction, when required, or Fisher's exact test was used. EpiInfo 6 was the statistical program used. The degree of significance accepted was $\leq 5 \%$.

\section{Results}

Mean age of men was lower than that of women (44.3 \pm 14.4 and 56.4 \pm 11.1 years, respectively, $\mathrm{p}=0.0061)$. The body surface of men was significantly greater than that of women $\left(1.67 \pm 0.12\right.$ and $1.51 \pm 0.10 \mathrm{~m}^{2}$, respectively, $\left.\mathrm{p}=0.00012\right)$. Fourteen $(63.6 \%)$ men and $11(61.1 \%)$ women were in NYHA class III/IV ( $\mathrm{p}=0.70)$. Incidence of angina, syncope and dyspnea was similar in both genders (table I). Dyspnea was present as an isolated symptom in 13 patients, and isolated syncope occurred in only one patient. Angina as an isolated symptom did not occur in any patient. Coexistence of these three symptoms was present in three patients, all female. Angina and dyspnea were present in 15; angina and syncope in eight, and dyspnea and syncope in five patients.

Incidence of SH was significantly greater in women than in men (10 versus 2 patients, respectively, $\mathrm{p}=0.0044$ ). However, when comparing the echocardiographic parameters of 10 women with SH and 8 without it, we did not find any difference in the left atrium (LA) diameter indices $(\mathrm{p}=0.44)$, end-diastolic $(\mathrm{p}=0.78)$ and end-systolic LV diameter $(\mathrm{p}=0.38), \mathrm{LVEF}(\mathrm{p}=0.60), \mathrm{LV}$ shortening fraction $(\mathrm{p}=0.75), \mathrm{LV}$ mass index (0.85) or RDT ( $\mathrm{p}=0.92)$ between both groups.

Degenerative AS was more common among women (12 versus 6, $\mathrm{p}=0.012$ ), and AS due to bicuspid aortic valve was more frequent in men ( 12 versus $1, \mathrm{p}=0.0031)$. The frequency of rheumatic AS, unicuspid valve and undetermined cause was the same for both genders (table I).

Doppler echocardiographic study showed that left ventricular-aortic pressure gradient was similar for both genders $(\mathrm{p}=0.57)$. LA diameter index $(\mathrm{p}=0.36)$, aortic root diameter index $(\mathrm{p}=0.068)$, ventricular septum $(\mathrm{p}=0.87)$ and PW $(p=0.79)$ thickness were equal in both genders. However, LV end-systolic diameter (SD) ( $\mathrm{p}=0.0022), \mathrm{LV}$ DD $(\mathrm{p}=0.027)$ and LV mass (0.017) indices were significantly higher among men. Women had significantly higher RDT $(\mathrm{p}=0.0095), \mathrm{EF}(\mathrm{p}=0.0032)$ and $\mathrm{FS}(\mathrm{p}=0.0046)$ values than men. Fourteen $(36.8 \%)$ patients had $\mathrm{EF}<50 \%, 4$ women and 10 men $(\mathrm{p}=0.18)$ (table II).

\section{Discussion}

Our study showed that individuals under 70 years of age have the same characteristics of geometry and left ventricular function observed in elder individuals with $\mathrm{AS}^{1-4}$. In addition, we showed that, despite the same clinical manifestations (table I) and the same severity of valve obstruction (table II), women with AS are older, have smaller body surface and greater incidence of degenerative AS than domen.

\begin{tabular}{|c|c|c|c|}
\hline \multicolumn{4}{|c|}{$\begin{array}{c}\text { Table I - Clinical characteristics and etiology of aortic stenosis in } \\
\text { men and women }\end{array}$} \\
\hline & Women $(\mathrm{n}=18)$ & Men $(n=22)$ & $\mathrm{p}$ \\
\hline Age (years) & $56.4 \pm 11.1$ & $44.3 \pm 14.4$ & 0.0061 \\
\hline $\mathrm{BS}\left(\mathrm{cm}^{2}\right)$ & $1.51 \pm 0.10$ & $1.67 \pm 0.12$ & 0.00012 \\
\hline NYHA III/IV (n) & 11 & 14 & 0.70 \\
\hline Angina (n) & 12 & 10 & 0.25 \\
\hline Syncope (n) & 9 & 4 & 0.97 \\
\hline Dyspnea (n) & 14 & 18 & 1 \\
\hline \multicolumn{4}{|l|}{ Etiology } \\
\hline Degenerative (n) & 12 & 6 & 0.012 \\
\hline Bicúspide (n) & 1 & 12 & 0.0031 \\
\hline Unicuspid (n) & 0 & 1 & 1 \\
\hline Rheumatic (n) & 3 & 0 & 1 \\
\hline Undetermined (n) & 2 & 3 & 1 \\
\hline $\begin{array}{l}\text { BS- body surface; } \\
\text { Heart Associatio }\end{array}$ & HA- functional & ccording to & Jew York \\
\hline
\end{tabular}

\begin{tabular}{|c|c|c|c|}
\hline & Women $(n=18)$ & Men $(n=22)$ & $\mathrm{p}$ \\
\hline $\mathrm{AO}\left(\mathrm{mm} / \mathrm{m}^{2}\right)$ & $18.9 \pm 2.2$ & $20.56 \pm 3.1$ & 0.068 \\
\hline $\mathrm{LA}\left(\mathrm{mm} / \mathrm{m}^{2}\right)$ & $23.5 \pm 5.5$ & $25.3 \pm 6.1$ & 0.36 \\
\hline $\mathrm{DD}\left(\mathrm{mm} / \mathrm{m}^{2}\right)$ & $32.1 \pm 6.5$ & $36.5 \pm 5.3$ & 0.027 \\
\hline $\mathrm{SD}\left(\mathrm{mm} / \mathrm{m}^{2}\right)$ & $19.9 \pm 5.9$ & $26.5 \pm 6.4$ & 0.0022 \\
\hline $\mathrm{VS}(\mathrm{mm})$ & $13.3 \pm 2.6$ & $13.2 \pm 2.1$ & 0.87 \\
\hline $\mathrm{PW}(\mathrm{mm})$ & $13.4 \pm 2.1$ & $13.2 \pm 2.3$ & 0.79 \\
\hline $\mathrm{EF}(\%)$ & $66.2 \pm 13.4$ & $52.0 \pm 14.6$ & 0.0032 \\
\hline $\mathrm{FS}(\%)$ & $37.6 \pm 10.7$ & $27.9 \pm 9.6$ & 0.0046 \\
\hline EDR & $0.58 \pm 0.22$ & $0.44 \pm 0.09$ & 0.0095 \\
\hline $\operatorname{MS}\left(\mathrm{g} / \mathrm{m}^{2}\right)$ & $211.4 \pm 72.1$ & $270.9 \pm 74.9$ & 0.017 \\
\hline Grad.VE/AO(mmHg) & $101.9 \pm 38.3$ & $96.1 \pm 25.8$ & 0.57 \\
\hline \multicolumn{4}{|c|}{$\begin{array}{l}\text { AO- aorta root diameter; LA- left atrium diameter; DD- LV end-diastolic } \\
\text { diameter; SD- LV end-systolic diameter; VS- diastolic thickness of the } \\
\text { ventricular septum; PW- diastolic thickness of the LV posterior wall; } \\
\text { EF- LV ejection fraction; FS- LV shortening fraction; RDT- LV relative } \\
\text { diastolic thickness; MS- LV mass; LV/AO Grad- pressure gradient } \\
\text { between left ventricle and aorta. }\end{array}$} \\
\hline
\end{tabular}


Relationship between ventricular geometry and function and patient age - Carrol et al ${ }^{1}$, analyzing 63 elderly patients with severe aortic stenosis, noted that for the same degree of valve obstruction, women's LV had a greater shortening fraction, a smaller $\mathrm{SD}$, more hypertrophic walls and smaller mass than men. Aurigemma et $\mathrm{al}^{3}$, studying 65 patients with AS and age $>60$ years, observed that women had the same ventricular mass as men and greater levels of peak intraventricular pressure, greater EF, smaller end-diastolic dimension, and greater RDT than men. Douglas et $\mathrm{al}^{2}$, in a study involving 232 elderly adults with AS according to the General Record of Balloon Valvoplasty of the National Heart, Lung and Blood Institute, observed that left ventricular geometry in women was different from that in men. Legget et $\mathrm{al}^{4}$, analyzing ventricular function at rest and during exercise, in 82 elderly asymptomatic patients with AS, observed that women had a greater impairment of the functional capacity, smaller end-diastolic and end-systolic volumes, smaller ventricular mass, greater RDT and greater shortening fraction than men. Impairment of the diastolic function was also more significant in women than in men. In addition, women showed a shorter exercise duration, greater degree of impairment of the aerobic functional capacity and a smaller elevation of the cardiac output with exercise than men. Pierri et $\mathrm{al}^{5}$, in a study involving 54 patients older than 80 years with AS, found results similar to the above cited, i.e., women had smaller ventricular volumes and greater EF than did men. Therefore, these studies involving elderly patients with AS show that, in this age group, LV geometry and function vary according to gender.

Would these alterations of the left ventricular geometry and function, dependent on patient gender, be a paradigm of the elderly population with severe aortic stenosis? - According to our study results, in individuals under 70 years of age with AS, ventricular geometry and systolic function have a similar behavior to that seen in the elderly ${ }^{1-5}$. Women have smaller LV diastolic and systolic dimensions, greater degree of hypertrophy, smaller mass and better left ventricular systolic function (EF and FS) than men, despite the same severity of valve obstruction (table II).

Analysis of these data suggest that gender, regardless of age, influences the compensatory process of chronic LV pressure overloads, with women maintaining more hypertrophic ventricles, smaller diameters and better systolic function than men. So far, there is no explanation for these findings ${ }^{10}$. Experiments performed on laboratory animals showed that there are physiologic and biochemical differences in the myocardium depending on animal gender ${ }^{11,12}$. We observed that women in our study had a greater incidence of SH than men ( $\mathrm{p}=0.0044)$. This finding led us to consider hypertension as the factor responsible for the different ventricular adaptation in women. However, the comparison of left ventricular function and geometry of hypertensive women with those of nonhypertensive women did not show any statistically significant difference.

Clinical implications - Hyperkinetic systolic function and adequate LVH do not mean, necessarily, a better prognosis for women with AS. Female gender is a bad and independent prognostic predictive factor, three years after balloon catheter aortic valvoplasty ${ }^{13}$. In addition, $\mathrm{LVH}$ is associated with increased cardiovascular risk and greater mortality in hypertensive patients ${ }^{14}$. Bad results were observed in women with $\mathrm{AS}$ after aortic valve replacement ${ }^{15}$, especially in those with greater RDT and smaller ventricular dimensions ${ }^{16}$. According to Orsinelli et al ${ }^{16}$, women with AS and RDT $>0.66$ who had undergone aortic valve replacement had operative mortality of $63 \%$ versus $14 \%$ of those with RDT $<0.66$. Analyzing operative mortality of the patients in our study reveals that women's mortality was significantly higher than that of men (4 deaths among women and none among men, $\mathrm{p}=0.033$ ).

Our study allows us to conclude that gender, rather than age, influences ventricular adaptive response to AS.

\section{References}

1. Carrol JD, Carrol EP, FeldmanT, et al. Sex-asssociated differences in left ventricular function in aortic stenosis of the elderly. Circulation 1992; 86: 1099-107.

2. Douglas PS, Otto CM, Michel MG, Labovitz A, Reid CL, Davis KB. Gender differences in left ventricular geometry and function in patients undergoing baloon dilation of the aortic valve for isolated aortic stenosis. Br Heart J 1995; 74: 548-54.

3. Aurigemma GP, Silver KH, McGaughlin M, Mausen J, Gaasch WH. Impact of chamber geometry and gender on left ventricular systolic function in patients $>60$ year of age with aortic stenosis. Am J Cardiol 1994; 74: 794-8.

4. Legget ME, Kuusisto J, Healy N, Fujio KM, Schwaegler RG, Otto CM. Gender differences in left ventricular function at rest and with exercise in asymptomatic aortic stenosis. Am Heart J 1996; 131: 94-100.

5. Pierri H, Décourt LV, Wajngarten M, et al. Perfil clínico de idosos portadores de estenose aórtica severa. Arq. Bras. Cardiol. 1997; 68: 415-20.

6. Sahn DJ, DeMaria A, Kisslo J, Weyman A. Recommendations regarding quantitation in M-mode echocardiography: results of a survey of echocardiographic measurements. Circulation 1978; 58: 1072-83.

7. Teicholtz LE, Kreulen T, Herman MV, Gorlin R. Problems in echocardiographic volume determinations: echocardiographic correlations in the presence or absence of asynergy. Am J Cardiol 1976; 37: 7-11.

8. Devereux R, Alonso DR, Lutas EM, et al. Echocardiographic assessment of left ventricular hypertrophy: comparison to necropsy findings. Am J Cardiol 1986; 57: 450-8.

9. Reichek N, Devereux R. Reliable estimation of peak left ventricular systolic pressure by M-mode echocardiographic-determined end-diastolic relative wall thickness: identification of severe valvular aortic stenosis in adults patients. Am Heart J 1982; 103: 202-3.

10. Aurigemma GP, Gaasch WH. Gender differences in older patients with pressureoverload hypertrophy of the left ventricle. Cardiology 1995; 86: 310-17.

11. Malhotra A, Schrible TF, Capasso J, Scheuer J. Correlation of myosin isoenzyme alterations with myocardial function in physiologic and pathologic hypertrophy. Eur Heart J 1984; 5(suppl F): 61-7.

12. Scheuer J, Malhotra A, Hirsch C, Capasso J, Schaiffe TF. Physiologic cardiac hypertrophy corrects contractile proteins abnormalities associated with pathologic hypertrophy in rats. J Clin Invest 1982; 70: 1300-5. 
13. Otto CM, Micckel MC, Kennedy JW, et al. Three year outcome after baloon aortic valvuloplasty. Insights into prognosis of valvular aortic stenosis. Circulation 1994; 89: 642-50.

14. Levy D, Garrison RJ, Savage DD, Kannel WB, Castelli WP. Prognostic implications of echocardiographically determined left ventricular mass in the Framingham Heart Study. N Engl J Med 1990; 322: 1561-6.
15. Aranski SF, Rizzo EJ, Couper GS, et al. Aortic valve replacement in the elderly. Effect of gender and coronary artery disease on operative mortality. Circulation 1993; 88(part 2): 17-23.

16. Orsinelli DA, Aurigemma GP, Battista S, Krendel S, Gaasch WH. Left ventricular hypertrophy and mortality after aortic valve replacement for aortic valve stenosis. J Am Coll Cardiol 1993; 22: 1679-83. 